\title{
Different Modalities to Assess Right Ventricular Function in Post-COVID Taking ST-Elevation as a Gold Standard and Arrhythmias in Post-COVID
}

\author{
Ritesh Khandelwal ${ }^{1 *}$, Preeti Gupta ${ }^{2}$, Sandeep Bansal ${ }^{2}$, Anunay Gupta ${ }^{2}$ \\ ${ }^{1}$ PhD., Clinical Research, Texila American University, Guyana \\ ${ }^{2}$ Department of Cardiology, Vardhman Mahavir Medical College and Safdarjung Hospital, \\ New Delhi, India
}

\begin{abstract}
The COVID-19 caused by novel single-stranded RNA enveloped severe acute respiratory syndrome coronavirus-2 (SARS CoV-2) first appeared in Wuhan, China. A lot of focus has been given to pulmonary complications. According to several case reports, cardiovascular associated clinical manifestations include myocarditis, arrhythmias, veno-thromboembolic events, acute coronary syndrome (ACS), and pericarditis. Different modalities in diagnosis like 2D, doppler can help in the early diagnosis of right ventricular function. This study evaluates the cardiac changes in recovered COVID-19 positive patients by $2 \mathrm{D}$ echocardiogram and other modalities. In this prospective observational study, 139 participants recently recovered from COVID-19 illness were identified and recruited after obtaining the Informed concerned form (ICF). The patients once enrolled were subjected to $2 D$ echo and ECG as part of routine clinical practice. Out of 139 patients, 89 (64.03\%) were males, and the rest were females. Based on the severity scale, 13 (9.35\%) participants had suffered a severe form of COVID-19 infection. Right ventricular functional assessment, right ventricular global strain (RVGLS) was abnormal in 72 (51.80\%) participants. Arrhythmias were reported in 31 (22.30\%) participants; among them, 30 participants had sinus bradycardia. Our study demonstrates the association between COVID-19 and cardiac changes/ incidence of cardiovascular complications in recovered COVID-19 patients. This study provides first-hand evidence of the incidence of abnormal LVGLS and RVGLS in COVID-19 recovered patients. In addition, there was a higher incidence of arrythmias.
\end{abstract}

Keywords: Cardiovascular outcomes, Post-COVID, Right ventricular function, ST elevation, $2 D$ echocardiography.

\section{Introduction}

The coronavirus disease of 2019 (COVID19) caused by novel single-stranded RNA enveloped severe acute respiratory syndrome coronavirus-2 (SARS CoV-2) first appeared in Wuhan, China [1, 2]. In March 2020, the World health organization (WHO) officially declared it a global pandemic because of the unusually fast rate of spread [1,2].

Respiratory symptoms mostly dominate clinical manifestations related to COVID-19, The most common severe complications are acute respiratory disease syndrome (ARDS) and systemic inflammatory response syndrome (SIRS), which can lead to multiorgan failure (MOF) and shock.

While a lot of focus has been given to pulmonary complications, clinicians need to equally evaluate the presence of cardiovascular complications, which can be a significant contributor to increased fatality in COVID-19 patients.

According to several case reports, cardiovascular associated clinical manifestations includemyocarditis [3, 4], arrhythmias, veno-thromboembolic events, 
acute coronary syndrome (ACS) [5], and pericarditis [6].

An early diagnosis of cardiac injury was seen in Chinese studies reported from the national health commission almost $11.8 \%$ of patients without the underlying cardiovascular disease had a cardiac injury during hospitalization, showed by elevated T- troponin (TnT) levels and new onset of electrocardiographic (ECG) /echocardiographic abnormalities [7]. Currently, the underlying mechanism behind the COVID-19 related cardiac injury is not clearly understood. However, various pathophysiological pathways are proposed; multifactorial direct and indirect mechanisms include $[8,9]$ :

1. Down regulation of ACE2 expression in the heart as demonstrated in a murine model of SARS-CoV-2 infection [10].

2. Cytokine storm.

3. Cyto-toxic effect on macrophages or interstitial cells within cardiac tissue [11].

4. Other mechanisms like low blood oxygen levels or hypoxia can lead to an intracellular influx of calcium ions, resulting in the apoptosis of cardiomyocytes [12].

This background indicates that SARS-CoV-2 infection is associated with a wide range of cardiovascular complications. Hence, this observational study is intended to evaluate Different modalities to assess $\mathrm{RV}$ function in post COVID taking STE as a Gold standard.

\section{Materials And Methods}

This prospective, single-center, observational study was planned to evaluate different modalities to assess RV function post COVID taking STE as a Gold standard. The patient was enrolled in the study only after obtaining written informed consent from them. Recruitment of 139 recovered COVID-19 patients was done to evaluate the association between COVID-19 infection and incidence of cardiovascular complications in recovered COVID-19 patients.
The patients who qualify for the study based on the inclusion and exclusion criteria were enrolled in the study after obtaining written informed consent. As mentioned in case report forms (CRF), medical history, vitals, and other parameters were captured at baseline.

The results were recorded in CRF, and the data obtained were analyzed post-completion of the study for all the patients.

\section{Inclusion Criteria}

Subjects meeting with following criteria were included in the study:

1. Male and female subjects aged 18 years $\&$ above.

2. Subjects who have tested positive for COVID-19 through the RT-PCR diagnostic test.

3. Subjects who have recovered from COVID19 infection and visit the hospital within three months of recovery.

4. Subjects who underwent treatment for COVID-19 at the hospital or in-home isolation.

5. Subjects who are willing to undergo the diagnostic tests (2D echo and ECG).

6. Subjects willing to provide informed written consent.

\section{Exclusion Criteria}

Subjects meeting with following criteria were excluded from the study:

1. Subjects whose cardiovascular condition can be attributed to other cardiac complications except for COVID-19 infection.

2. Subjects who have pre-existing cardiac conditions.

3. Subjects with any other illness or health condition in the study investigator's opinion/medical judgment make the subject ineligible to participate in the study.

\section{Statistical analysis}

Following data collection, the obtained data was transferred from paper CRFs into an excel sheet for analysis. All statistical analysis was 
performed using the software 'STATA version 15.0'. All data were summarized descriptively. For continuous variables, data was represented using means \pm SD. For categorical data, the number and percentages were used in the data summaries.

\section{Results}

A total of 139 COVID-19 recovered patients were enrolled in our study after taking written consent from all the participants for participating in this prospective observational study. The mean age of the participants was $38.57 \pm 12.10$ years. Among these 139 COVID19 recovered patients, $64.03 \%$ (89) were males, and the rest were females. Thus, a significant proportion of $77.70 \%$ (108) study population was reported to have a mild type of COVID-19 severity followed by $12.95 \%$ (18) having moderate type and $9.35 \%$ (13) suffering from a severe form of COVID-19, as shown in Table
As shown in Table 2, 28.78\% (40) of the study population was obese. While Hypertension (HTN), diabetes mellites (DM), and hypothyroidism with 27 (19.42\%), 12 $(8.63 \%)$, and $10(7.19 \%)$ were the second, third, and fourth most common medical conditions present in our study population, respectively.

ECG was performed on 139 (100.00\%) patients, and on only $60(43.16 \%)$ patient's chest X-ray was performed.

$51.80 \%$ (72) COVID-19 recovered patients had abnormal RV dysfunction and abnormal global longitudinal strain for right ventricular function (RVGLS). (Table 3) These were done using color flow mapping and doppler studies.

In total, $31(22.30 \%)$ patients were diagnosed with arrhythmias, and within them, a large proportion of 30 patients were reported to be suffering from SINUS TACHYCARDIA, as shown in Table 4.

Table 1. Demographic Details of the Patients

\begin{tabular}{|l|l|}
\hline Parameters & N = 139 \\
\hline Age (years) & $38.57 \pm 12.10$ \\
\hline Gender & \multicolumn{2}{|l|}{} \\
\hline Male & $89(64.03 \%)$ \\
\hline Female & $50(35.97 \%)$ \\
\hline Height $(\mathrm{cm})$ & $163.52 \pm 9.60$ \\
\hline Weight $(\mathrm{Kg})$ & $69.56 \pm 12.39$ \\
\hline Body surface area (m2) & $1.70 \pm 0.19$ \\
\hline Systolic blood pressure $(\mathrm{mm} \mathrm{Hg})$ & $132.23 \pm 17.77$ \\
\hline Diastolic blood pressure $(\mathrm{mm} \mathrm{Hg})$ & $85.14 \pm 9.68$ \\
\hline Heart rate (Beat/min) & $92.56 \pm 14.02$ \\
\hline Severity in $(\%)$ & \\
\hline Mild & $108(77.70 \%)$ \\
\hline Moderate & $18(12.95 \%)$ \\
\hline Severe & $13(9.35 \%)$ \\
\hline
\end{tabular}

Table 2. Medical History Details of the Patients

\begin{tabular}{|l|l|}
\hline Parameters & N = 139 \\
\hline Diabetes mellitus, $\mathrm{n}(\%)$ & $12(8.63 \%)$ \\
\hline Hypertension, n (\%) & $27(19.42 \%)$ \\
\hline Smokers, n (\%) & $16(11.51 \%)$ \\
\hline Alcoholics, n (\%) & $12(8.63 \%)$ \\
\hline
\end{tabular}




\begin{tabular}{|l|l|}
\hline Obese, n (\%) & $40(28.78 \%)$ \\
\hline Hypothyroid, n (\%) & $10(7.19 \%)$ \\
\hline Snoring, n (\%) & $56(40.29 \%)$ \\
\hline ECG performed, n (\%) & $139(100.00 \%)$ \\
\hline X-ray (chest) performed, n (\%) & $60(43.16 \%)$ \\
\hline
\end{tabular}

Table 3. Assessment of Right Ventricular Dysfunction by Color Flow Mapping and Doppler Studies

\begin{tabular}{|l|l|}
\hline Parameters & Result (N= 139) \\
\hline Normal LV systolic function & $139(100.00 \%)$ \\
\hline Right ventricular dysfunction \\
\hline Normal & $67(48.20 \%)$ \\
\hline Abnormal & $72(51.80 \%)$ \\
\hline Global strain of R.V., n (\%) \\
\hline Normal & $67(48.20 \%)$ \\
\hline Abnormal & $72(51.80 \%)$ \\
\hline
\end{tabular}

Table 4. Details of Occurrence of Arrhythmias in Patients

\section{Discussion}

In this prospective observational study of predominantly COVID-19 recovered patients, Echocardiography allows the noninvasive assessment of biventricular function and can provide important insights into possible mechanisms [13]. A recent meta-analysis conducted on seven studies concludes that lower RVGLS and LVGLS were independently associated with poor outcomes in COVID-19 recovered patients [14]. In our study, $51.80 \%$ of patients were having reduced or abnormal RVGLS. Lassen et al. also reported lower RVLS in patients with COVID-19 than those without it [15]. A smaller study showed that there was no significant difference in terms of RV-GLS between those without COVID-19, with COVID-19, and COVID-19 + increased cardiac troponin [16].

A study showed no significant difference in RV-GLS in non-survivors compared to

\section{Result (N= 139)}

$31(22.30 \%)$

$108(77.0 \%)$

$1(0.72 \%)$

$30(21.58)$

survivors; this is likely due to the high Prevalence of hypertension in the patients. As hypertension is expected to reduce the RV-GLS $[17,18]$.

As most of the studies conducted in this area of research [21, 27-29], our study population was also middle-aged, predominantly male (64.03\%) with $77.01 \%$ mild COVID-19 severity. As seen in previously reported studies, this study population also has a high prevalence of co-morbidities like obesity (28.78\%), hypertension (19.42\%), diabetes mellitus (8.63\%), and hypothyroidism (7.9\%). Smoking and alcohol consumption was seen more frequently in our study population when compared to other studies $[19,20]$.

This study comprehensively evaluates the Right ventricular function using conventional Echocardiography and 2DSTE in patients with COVID-19; it is very well known that patients having a greater degree of RV strain impairment were more likely to have higher 
heart rate, more high flow oxygen, higher incidence of acute heart injury, acute respiratory distress syndrome (ARDS) and higher mortality.

According to the recommendations of standard guidelines, RV function should be evaluated using conventional Echocardiography- parameters [21], which include TAPSE, RVFAC\%, and S', but recently 2DSTE has also been recommended as a superior method to assess RV function.

In our study population, a total of 72 (51.80\%) COVID-19 recovered patients were found to have abnormal RV strain; various studies revealed that it is a strong prognostic indicator for various cardiovascular diseases, [22-24] and TV dysfunction is not only a sign of increased pulmonary pressure but also directly contributes to cardiac insufficiency.

COVID-19 related cardiac arrhythmias were first reported by [25] and colleagues; they reported a $17 \%$ incidence of arrhythmias. Like this report, our study reports $22.30 \%$ of arrhythmias in our study population. A study by

\section{References}

[1] CDC. (2020, March 28). Covid data tracker. Centers for Disease Control and Prevention. https://covid.cdc.gov/covid-data-tracker.

[2] WHO coronavirus (COVID-19) dashboard. (n.d.). Retrieved 27 July 2021, from https://covid19. who.int.

[3] Luetkens, J. A., Isaak, A., Zimmer, S., Nattermann, J., Sprinkart, A. M., Boesecke, C., Rieke, G. J., Zachoval, C., Heine, A., Velten, M., \&Duerr, G. D., 2020, Diffuse myocardial inflammation in covid-19 associated myocarditis detected by multiparametric cardiac magnetic resonance imaging. Circulation: Cardiovascular Imaging, 13(5).

https://doi.org/10.1161/CIRCIMAGING.120.010897.

[4] Rajpal, S., Tong, M. S., Borchers, J., Zareba, K. M., Obarski, T. P., Simonetti, O. P., \& Daniels, C. J., 2021, Cardiovascular Magnetic Resonance Findings in Competitive Athletes Recovering From
[26] reported a $24 \%$ incidence of arrhythmias among COVID-19 patients. In some more severe cases of COVID-19, $60 \%$ of cases had arrythmias. This can be attributed to the fact that SARS-CoV 2 is distinctly classified in the beta coronavirus family, belongs to the same genus as SARS-CoV, and MERS-CoV both of which had a long history of causing cardiovascular complications post-infections [27-29].

\section{Conclusion}

Our study had demonstrated that there is a high incidence of cardiovascular complications in recovered COVID-19 patients by assessing their RVGLS. Accordingly, the present study also revealed the importance of utilizing standard diagnosing tools like 2Dechocardiogram and electrocardiogram to monitor cardiovascular-related complications in recovered COVID-19 patients.

\section{Conflicts of Interest}

We have no conflict of interest to declare.

COVID-19 Infection. JAMA cardiology, 6(1), 116118. https://doi.org/10.1001/jamacardio.2020.4916. [5] Bangalore, S., Sharma, A., Slotwiner, A., Yatskar, L., Harari, R., Shah, B., Ibrahim, H., Friedman, G. H., Thompson, C., Alviar, C. L., Chadow, H. L., Fishman, G. I., Reynolds, H. R., Keller, N., \& Hochman, J. S. (2020). ST-Segment Elevation in Patients with Covid-19 - A Case Series. The New England Journal of Medicine, 382(25), 2478-2480.

https://doi.org/10.1056/NEJMc2009020.

[6] Sauer, F., Dagrenat, C., Couppie, P., Jochum, G., Leddet, P., D’Amario, D., Asher, E., Rudzínski, P. N., Camm, C. F., \& Thomson, R., 2020, Pericardial effusion in patients with COVID-19: Case series. European Heart Journal - Case Reports, 4(FI1). https://doi.org/10.1093/ehjcr/ytaa287.

[7] Zheng, Y. Y., Ma, Y. T., Zhang, J. Y., \& Xie, X, 2020, COVID-19 and the cardiovascular system. Nature reviews. Cardiology, 17(5), 259-260. https://doi.org/10.1038/s41569-020-0360-5. 
[8] Wu, L., O’Kane, A. M., Peng, H., Bi, Y., Motriuk-Smith, D., \& Ren, 2020, SARS-CoV-2 and cardiovascular complications: From molecular mechanisms to pharmaceutical management. Biochemical pharmacology, 178, 114114. https://doi.org/10.1016/j.bcp.2020.114114.

[9] Nishiga, M., Wang, D. W., Han, Y., Lewis, D. B., \& Wu, J. C, 2020, COVID-19 and cardiovascular disease: from basic mechanisms to clinical perspectives. Nature reviews. Cardiology, 17(9), 543-558. https://doi.org/10.1038/s41569-020-04139.

[10] Oudit, G. Y., Kassiri, Z., Jiang, C., Liu, P. P., Poutanen, S. M., Penninger, J. M., \& Butany, J, 2009, SARS-coronavirus modulation of myocardial ACE2 expression and inflammation in patients with SARS. European Journal of Clinical Investigation, 39(7), 618-625. https://doi.org/10.1111/j.13652362.2009.02153.x.

[11]Lindner, D., Fitzek, A., Bräuninger, H., Aleshcheva, G., Edler, C., Meissner, K., Scherschel, K., Kirchhof, P., Escher, F., Schultheiss, H. P., Blankenberg, S., Püschel, K., \& Westermann, D, 2020, Association of Cardiac Infection With SARSCoV-2 in Confirmed COVID-19 Autopsy Cases. JAMA cardiology, 5(11), 1281-1285. https://doi.org/10.1001/jamacardio.2020.3551.

[12]Li, B., Yang, J., Zhao, F., Zhi, L., Wang, X., Liu, L., Bi, Z., \& Zhao, Y, 2020, Prevalence and impact of cardiovascular, metabolic diseases on COVID-19 in China. Clinical research in cardiology: Official Journal of the German Cardiac Society, 109(5), 531-538. https://doi.org/10.1007/s00392-020-01626-9.

[13] Churchill, T. W., Bertrand, P. B., Bernard, S., Namasivayam, M., Churchill, J., Crousillat, D., Davis, E. F., Hung, J., \& Picard, M. H, 2020, Echocardiographic Features of COVID-19 Illness and Association with Cardiac Biomarkers. Journal of the American Society of Echocardiography: Official Publication of the American Society of Echocardiography, 33(8), 1053-1054. https://doi.org/10.1016/j.echo.2020.05.028.

[14]Levin, V. A., Rodriguez, L. A., Edwards, M. S., Wara, W., Liu, H. C., Fulton, D., Davis, R. L., Wilson, C. B., \& Silver, P, 1988, treatment of medulloblastoma with procarbazine, hydroxyurea, and reduced radiation doses to whole brain and spine. Journal of Neurosurgery, 68(3), 383-387. https://doi.org/10.3171/jns.1988.68.3.0383, 68,3837.

[15]Lassen, M., Skaarup, K. G., Lind, J. N., Alhakak, A. S., Sengeløv, M., Nielsen, A. B., Espersen, C., Ravnkilde, K., Hauser, R., Schöps, L. B., Holt, E., Johansen, N. D., Modin, D., Djernaes, K., Graff, C., Bundgaard, H., Hassager, C., Jabbari, R., Carlsen, J., Lebech, A. M., ... Biering-Sørensen, T, 2020, Echocardiographic abnormalities and predictors of mortality in hospitalized COVID-19 patients: the ECHOVID-19 study. ESC heart failure, 7(6), 4189-4197. Advance Online Publication. https://doi.org/10.1002/ehf2.13044.

[16]Lairez, O., Blanchard, V., Houard, V., VardonBounes, F., Lemasle, M., Cariou, E., Lavie-Badie, Y., Ruiz, S., Cazalbou, S., Delmas, C., Georges, B., Galinier, M., Carrié, D., Conil, J. M., \& Minville, V, 2021, Cardiac imaging phenotype in patients with coronavirus disease 2019 (COVID-19): results of the cocarde study. The International Journal of Cardiovascular Imaging, 37(2), 449-457. https://doi.org/10.1007/s10554-020-02010-4.

[17] Goerlich, E., Gilotra, N. A., Minhas, A. S., Bavaro, N., Hays, A. G., \& Cingolani, O. H, 2021, Prominent Longitudinal Strain Reduction of Basal Left Ventricular Segments in Patients with Coronavirus Disease-19. Journal of Cardiac Failure, 27(1), 100-104. https://doi.org/10.1016/j.cardfail.2020.09.469.

[18] Chan, J., Hanekom, L., Wong, C., Leano, R., Cho, G. Y., \& Marwick, T. H, 2006, Differentiation of subendocardial and transmural infarction using two-dimensional strain rate imaging to assess shortaxis and long-axis myocardial function. Journal of the American College of Cardiology, 48(10), 20262033. https://doi.org/10.1016/j.jacc.2006.07.050.

[19] Soulat-Dufour, L., Lang, S., Ederhy, S., Adavane-Scheuble, S., Chauvet-Droit, M., Nhan, P., Jean, M. L., Ben Said, R., Issaurat, P., Boccara, F., \& Cohen, A, 2020, Left ventricular ejection fraction: An additional risk marker in COVID-19. Archives of cardiovascular diseases, 113(11), 760-762. https://doi.org/10.1016/j.acvd.2020.08.002. 
[20]Li, Y., Li, H., Zhu, S., Xie, Y., Wang, B., He, L., Zhang, D., Zhang, Y., Yuan, H., Wu, C., Sun, W., Zhang, Y., Li, M., Cui, L., Cai, Y., Wang, J., Yang, Y., Lv, Q., Zhang, L., \& Xie, M, 2020, Prognostic Value of Right Ventricular Longitudinal Strain in Patients With COVID-19. JACC. Cardiovascular Imaging, 13(11), 2287-2299. https://doi.org/10.1016/j.jcmg.2020.04.014.

[21] Rudski, L. G., Lai, W. W., Afilalo, J., Hua, L., Hand Schumacher, M. D., Chandrasekaran, K., Solomon, S. D., Louie, E. K., \& Schiller, N. B, 2010, Guidelines for the echocardiographic assessment of the right heart in adults: a report from the American Society of Echocardiography endorsed by the European Association of Echocardiography, a registered branch of the European Society of Cardiology, and the Canadian Society of Echocardiography. Journal of the American Society of Echocardiography: official publication of the American Society of Echocardiography, 23(7), 685788. https://doi.org/10.1016/j.echo.2010.05.010.

[22] Carluccio, E., Biagioli, P., Alunni, G., Murrone, A., Zuchi, C., Coiro, S., Riccini, C., Mengoni, A., D’Antonio, A., \& Ambrosio, G, 2018, Prognostic Value of Right Ventricular Dysfunction in Heart Failure with Reduced Ejection Fraction: Superiority of Longitudinal Strain Over Tricuspid Annular Plane Systolic Excursion. Circulation. Cardiovascular Imaging, $\quad$ 11(1), e006894. https://doi.org/10.1161/CIRCIMAGING.117.006894.

[23] Medvedofsky, D., Koifman, E., Jarrett, H., Miyoshi, T., Rogers, T., Ben-Dor, I., Satler, L. F., Torguson, R., Waksman, R., \& Asch, F. M, 2020, Association of Right Ventricular Longitudinal Strain with Mortality in Patients Undergoing Transcatheter Aortic Valve Replacement. Journal of the American Society of Echocardiography: official publication of the American Society of Echocardiography, 33(4), 452-460.

https://doi.org/10.1016/j.echo.2019.11.014.
[24] Mast, T. P., Taha, K., Cramer, M. J., Lumens, J., van der Heijden, J. F., Bouma, B. J., van den Berg, M. P., Asselbergs, F. W., Doevendans, P. A., \& Teske, A. J, 2019, The Prognostic Value of Right Ventricular Deformation Imaging in Early Arrhythmogenic Right Ventricular Cardiomyopathy. JACC. Cardiovascular Imaging, 12(3), 446-455. https://doi.org/10.1016/j.jcmg.2018.01.012.

[25] Wang, D., Hu, B., Hu, C., Zhu, F., Liu, X., Zhang, J., Wang, B., Xiang, H., Cheng, Z., Xiong, Y., Zhao, Y., Li, Y., Wang, X., \& Peng, Z, 2020, Clinical Characteristics of 138 Hospitalized Patients With 2019 Novel Coronavirus-Infected Pneumonia in Wuhan, China. JAMA, 323(11), 1061-1069. https://doi.org/10.1001/jama.2020.1585.

[26]Lei, S., Jiang, F., Su, W., Chen, C., Chen, J., Mei, W., Zhan, L. Y., Jia, Y., Zhang, L., Liu, D., Xia, Z. Y., \& Xia, Z, 2020, Clinical characteristics and outcomes of patients undergoing surgeries during the incubation period of COVID-19 infection. E-Clinical Medicine, 21, 100331. https://doi.org/10.1016/j.eclinm.2020.100331.

[27] Yu, C. M., Wong, R. S., Wu, E. B., Kong, S. L., Wong, J., Yip, G. W., Soo, Y. O., Chiu, M. L., Chan, Y. S., Hui, D., Lee, N., Wu, A., Leung, C. B., \& Sung, J. J, 2006, Cardiovascular complications of severe acute respiratory syndrome. Postgraduate Medical Journal, 82(964), 140-144. https://doi.org/10.1136/pgmj.2005.037515.

[28] Wang, Y., Wang, Z., Tse, G., Zhang, L., Wan, E. Y., Guo, Y., Lip, G., Li, G., Lu, Z., \& Liu, T, 2020, Cardiac arrhythmias in patients with COVID19. Journal of Arrhythmia, 36(5), 827-836. https://doi.org/10.1002/joa3.12405.

[29]He, X. W., Lai, J. S., Cheng, J., Wang, M. W., Liu, Y. J., Xiao, Z. C., Xu, C., Li, S. S., \& Zeng, H. S, 2020, Zhonghua xin xue guan bing za zhi, 48(6), 456-460. https://doi.org/10.3760/cma.j.cn11214820200228-00137. 